\title{
Constraining argument structure in nominalizations: The case of English -er
}

The article contributes to the typology of structural factors constraining argument realization in nominalizations, focussing on English -er-nominals. It reappraises conclusions of earlier studies on when -er-nominals allow argument realization. Derivations disallowing argument linking are treated as semantically and structurally parallel to nominal compounds, and their argument-structural behaviour is attributed to a generalization that non-heads of basegenerated complex heads cannot realize arguments, with principled exceptions. In argumentrealizing -er-nominals, some speakers allow the full range of argument structures permitted by head movement analyses, while less liberal varieties require a (lexicalist-inspired but syntactically implemented) analysis where $-e r$ is an Agent-realizing affix that selects $\mathrm{V}^{\circ}$, forcing arguments of $\mathrm{V}$ to merge above affixation as arguments of nouns, which is only possible for PP and of-insertion arguments.

Keywords: nominalization, argument structure, compounds, affixation, eventiveness

\section{Introduction}

A central problem concerning the interfaces between syntax, semantics and morphology is that category-changing processes disallow the realization (inheritance) of the arguments of the related verb to varying degrees, as seen in (1)-(3).

a. The tuner of the guitar was Mary.

b. the \{guitar tuner/tuner (*of guitars)\} in the drawer

c. ${ }^{(*)}$ the discoverers that the world is round

d. * a maker of linguists happy

(2)

the $\{$ breaking/*break\} of his leg

(3) an amputee $\left({ }^{(*)}\right.$ of a leg)

Nominalizations with -er like those in (1) have attracted considerable attention as a revealing problem for theories of argument structure (e.g. Levin \& Rappaport 1988, van Hout \& Roeper 1998, Alexiadou \& Schäfer 2010, Borer 2013, Roy \& Soare 2014), but I argue that not all empirical generalizations in previous work are correct and that data like (1) require explanations which do not figure in previous accounts of nominalizations.

One innovation proposed here concerns nominalizations like (1b) which block all (phrasal) arguments of their parent verbs. After describing problems with existing accounts of these, I argue that of-phrases are excluded for the same reasons as those in compounds like tuning device (*of guitars). The generalization is that (phrasal) arguments of base-generated complex heads cannot be realized, with certain exceptions which are given principled explanations.

Another claim made here concerns uses of -er like (1a) which do allow inheritance of arguments. Non-lexicalist studies standardly assume that such nominalizations involve head movement (e.g. Alexiadou \& Schäfer (2010), Baker \& Vinokurova (2009), Borer (2013), Bowers (2011), Harley (2008), Roy \& Soare (2014)). Such approaches share two assumptions: (i) the nominalizing affix is a syntactic head which selects a phrasal projection containing $\mathrm{V}$ and its arguments (VP in (4a)), and (ii) $\mathrm{V}$ undergoes head movement to the nominalizer to form a derived nominal such as washing, washer. (Both assumptions hold regardless of differences between accounts regarding the size of the constituent initially selected by the affix, and how of-marking of V's argument is implemented.)

a. [NP-ing/-er [vp wash [DP/PP (of) hands]]]

b. $\left[\mathrm{NP}\left[\mathrm{N}^{\circ}\left[\mathrm{v}^{\circ}\right.\right.\right.$ wash $\left.]-i n g /-e r\right][\mathrm{DP} / \mathrm{PP}($ of) hands $]]$

By contrast, lexicalist studies standardly capture argument inheritance phenomena using structures like (4b), (e.g. Ackema \& Neeleman (2004:23-27), Grimshaw (1990:71)). The affix attaches directly to V. Unlike what is witnessed in (4a), V's argument is realized after nominalization, as an argument of $N$. Thus V's argument selection features are not realized 
immediately, but 'percolate' to the affix selecting V. Such long-distance argument realization should not be the default hypothesis. However, I argue that configurations like (4b) must exist, as they readily explain the negative judgments of some speakers in $(1 \mathrm{c}, \mathrm{d})$, which are unexpected in head movement approaches.

The proposals here can be adopted in both lexicalist and syntactic theories. The structure in (4b) is inspired by lexicalist writings, but I express it in a purely syntactic approach. The criticisms of head movement approaches like (4a) apply to certain uses of -er but not necessarily to other affixes.

We proceed as follows. Section 2 describes the differences between argument-inheriting and non-argument-inheriting -er-nominals, noting problems with existing accounts. Section 3 discusses -er-nominalizations that disallow (phrasal) arguments, assimilating their behavior to that of compounds. Section 4 treats argument-inheriting -er-nominals, noting that they eschew AP and clausal arguments in some idiolects and presenting an analysis where the arguments tolerated in the less liberal varieties are merged after affixation.

\section{Two types of $-e r$-nouns: $-e r^{\mathrm{Ev}}$ vs. $-e r^{\mathrm{nonEv}}$}

\subsection{Correlations between eventiveness and argument realization}

Studies of nominalizations frequently assume that argument-inheriting nominalizations refer to events in ways that non-argument-supporting nominalizations do not. This view is common for event nominalizations like (2) (e.g. Grimshaw 1990, Borer 2013) and for -er-nominals (e.g. Rappaport \& Levin 1992, van Hout \& Roeper 1998, Alexiadou \& Schäfer 2006, Roy \& Soare 2014). The latter studies distinguish between an eventive, argument-inheriting use of -er, here called $-\boldsymbol{e r}^{\mathrm{Ev}}$, and a non-eventive use, $-\boldsymbol{e r} \boldsymbol{r}^{\mathbf{n o n E v}}$, that does not support (phrasal) arguments. One symptom of eventiveness is compatibility with event-modifying expressions like frequent, constant, habitual (see especially Roy \& Soare 2014). (5) suggests that these are possible with of-arguments but not compounds (with qualifications discussed shortly; the judgments hold if lifesaver means 'lifeguard' and can opener means 'can opening device').

a. frequent \{savers of lives/openers of cans\}

b. (*frequent) $\{$ lifesavers/can openers $\}$

Another eventiveness effect is an event entailment: of-insertion-er-nominals entail the occurrence of the event named by the parent verb, while other-er-nouns do not (again with exceptions seen below). A washer of clothes must have washed clothes while a device called a clothes washer need not have. Analogous remarks hold for (6). ${ }^{1}$
a. saver of lives, fighter of fires, opener of cans
b. lifesaver, fire fighter, can opener
[event entailments]
[no event entailments]

A previously unobserved complication is that eventiveness effects are not exclusively found with of-nominals. The compound and bare -er-nominals in (7)a,b) have event entailments (or state entailments with lover, admirer), and those in (7)c,d) allow eventive modifiers.

\footnotetext{
${ }^{1}$ I know of two apparent cases where of-arguments exist in non-eventive contexts. First, in my judgment teachers/instructors of physics might refer to individuals with qualifications but without teaching experience. Here the of-phrases are, I suggest, not realizers of arguments of nominalized verbs, but genitives licensed in the same way as those found with semantically similar synchronically underived nominals like professor/tutor of physics. Second, the -er-of-nominals in (i) and (ii) only entail possible events, which tempts us to equate them with $-e r^{\text {nonEv }}$-nominals like firefighter. However, the -er-nominals in (i)/(ii) are embedded in conditional contexts (e.g. (i) means 'if anyone drinks the wine they will sleep eternally') and this obscures their intrinsic eventive interpretation, which they clearly exhibit in non-conditional contexts like the drinker of the wine fell asleep. Furthermore, the existence of referents for the -er-nominals in (i)/(ii) depends on the occurrence of the drinking/finding events, unlike what is seen with $-e r^{\text {nonEv }}$-nominals like firefighter, law enforcer.

(i) The drinker of the wine will fall into an eternal sleep. (Olsen 1992:23)

(ii) The finder of this wallet should ring 123-45678.
} 
a. cow worshiper, draft dodger, child molester, prize winner, wine lover/drinker

b. discoverer, smoker, lover, admirer

c. frequent \{dope smokers/card players/teeth cleaners\}

d. frequent \{flyers/drinkers/overworkers\}

Thus far we can generalize that -er-of-nominals must have eventive interpretations while other -er-nouns can do so in some cases. To clarify this we must understand the interpretation of $-e r^{\text {nonEv }}$-nouns. I assume that most of these have functional interpretations: they name entities whose intrinsic or designated purpose or function is to participate in the event named by the affixed V. This subsumes artefacts designed for particular uses (printer, lawnmower) and humans in professional or temporary functions (teacher, minutes taker). Other $-e^{\text {nonEv }}$ nouns have dispositional interpretations (Alexiadou \& Schäfer 2010, Roy \& Soare 2014): their referents have properties predisposing them for participation in particular events, consider heartbreakers 'people with a potential/disposition to break hearts'. Section 2.3 argues that most $-e r^{\text {nonEv }}$-nouns have functional interpretations while some have dispositional ones. What is important here is that both interpretations lack event entailments: printers, minutes takers and heartbreakers need never have printed, taken minutes or broken hearts; their functions or dispositions might be as yet unrealized.

We can now explain the inconsistent degrees to which non-of-insertion -er-nominals tolerate eventive behavior. Standard judgments like (5)b) and (6)b) hold of the functional readings of lifesaver, firefighter, can opener, which are salient, entrenched uses of these nouns. Looking beyond the uses of the nouns as names for professions/instruments, we find eventive uses. Thus, internet attestations of frequent lifesavers evoke not the functional interpretation 'lifeguard', but an eventive one ('people/things which have (metaphorically) saved lives'). By contrast, nominals like cow worshiper, smoker and others in (7) lack salient functional readings which could preempt the eventive ones, since actions like cow-worshiping or smoking are not normally seen as functions of people. ${ }^{2}$

We now describe more fully the argument-structural properties of the two classes of -ernominals. $-e r^{\text {nonEv }}$-nouns seem oblivious to the argument structures of their parent verbs. They disallow of-phrases realizing arguments of $\mathrm{V}$. Their referents are not confined to particular thematic roles and sometimes flout V's selection restrictions, witness the taxonomy in (8) (partly inspired by Ryder 1999). $-e r^{\text {nonEv }}$ would be sensitive to argument structure if Levin \& Rappaport (1988:1072; L\&R) were right in claiming that instrument -er-nominals must be potential subjects of their corresponding verbs, but this claim is incorrect, cf. *This poker pokes fires well, and likewise for guitar tuner, inhaler, puffer, letter opener, scraper and stirrer 'stirring spoon'. L\&R's argument that formations like (8)c) correspond to subjects of middles (roaster vs. the chicken roasts well) will not work for cases like keeper 'thing to be kept' (cf. *Jewelry keeps easily) and for (8)d) (*This swimsuit bathes (in) well). Finally, -er realizes no argument of $\mathrm{V}$ in (8)e). I thus assume that $-e^{\mathrm{nonEv}}$ does not realize an argument of $\mathrm{V}$, even in cases like $(8) \mathrm{b}, \mathrm{c})$ where the nominals happen to correspond to arguments of the parent verb in clauses (cf. Barker's 1998 evidence that -ee- in cases like trainee does not realize V's Patient argument). V's argument structure could only be said to be relevant to $-e r^{\mathrm{nonEv}}$-nominals if nonheads of compounds like can opener, lifesaver are true argument realizers, a controversial issue addressed in section $3.3 .^{3}$

\footnotetext{
${ }^{2}$ I see no comparable pragmatic reason why smoker could not have a dispositional reading describing someone who has never smoked but has an addictive personality predisposed to smoking. However, smoker cannot have this interpretation (outside coercive contexts like potential/born smoker) because, as noted in section 2.3, the dispositional reading of $-e r^{\text {nonEv }}$ is less productive than the functional one.

${ }^{3}$ The conclusion that $-e r^{\text {nonEv }}$ does not realize arguments holds regardless of whether one sees the uses in (8) as distinct or as instantiations of one underspecified relation to the verbal event-kind. A challenge for unified analyses is that uses like (8)c-e) seem less productive than those in (8)a,b). However, the former are not unproductive (Ryder 1999), and their appearance of limited productivity is perhaps exaggerated by trivial factors like ambiguity avoidance and blocking (trainee blocks the patient reading of trainer; the well-established
} 
a. INSTRUMENT: paint scraper, stapler, lens cleaner, polish remover

b. AGENT: teacher (with no work experience), tax collector, law enforcer

c. PATIENT/THEME: locker 'lockable cupboard', reader 'type of book', fixer-upper 'house to be fixed up'

d. LOCATION: kneeler 'thing to kneel on', scribbler, jotter, bathers 'swimsuit'

e. INDIRECT CAUSER (no argument of V): foot tapper/headbanger 'song apt to cause people to tap feet/bang heads', nail biter 'situation apt to cause nervous nail-biting', steam-letter-offer 'pastime allowing one to let off steam', page-turner 'book apt to induce compulsive page-turning'

By contrast, $-e r^{\mathrm{Ev}}$-nouns are sensitive to the affixed verb's argument structure. They allow realization of the parent verb's direct objects as of-phrases, see e.g. (6)a). Arguments of other categories are also realizable (frequent contributors to books), modulo constraints seen in section 4. Moreover, $-e r^{\mathrm{Ev}}$-nominals always correspond to external arguments of the base verbs, including Agents, inanimate Causes (9)a), non-agentive Recipients/Possessors (9)b) or non-agentive Experiencers (9)c). I use Initiator as a superordinate term for all such participants. Like e.g. Actor in Role and Reference Grammar, the term is named after the core cases of arguments realized as external arguments. In line with theories using generalized semantic roles (Dowty 1991, van Valin 1999, Naess 2006), I assume that, to varying degrees in different languages, less prototypical Initiators like the possessors or experiencers in $(9) b, c)$ are realized grammatically in the same way as Agents because they share with them certain properties like sentience or control. ${ }^{4}$

(9) a. adultery is a wrecker of families; oil is a frequent causer of wars; pain is a saver of lives; it is a thriller of the mind; carpet is an accumulator of dust

b. frequent receivers of prizes; owners of shares

c. habitual admirers/despisers of non-conformists

d. *dier, *collapser, *faller, *long-laster, *disappearer, *enterer

e. frequent \{early riser/churchgoer/latecomer/late arriver/travelers to Spain

Since $-e r^{\mathrm{Ev}}$ realizes external Initiator arguments, it should be incompatible with unaccusative verb uses, but judgments like those in (9)d,e) (cf. L\&R 1075, 1081) only partly confirm this, and some decontextualized judgments like (d) are disconfirmed by internet searches. I suggest that speakers who allow these construe the participants as Initiators (as Agents, or as Internal Causers in attestations like early dier) and are treating the parent verbs as unergative. I cannot explore this hypothesis here. If it is wrong we must posit a distinct (possibly only semiproductive) use of $-e r^{\mathrm{Ev}}$ which can be studied separately from the -er-uses described here.

The properties of the two readings of -er are summarized in (10).

(10) a. $-e r^{\mathrm{Ev}}$-nouns are eventive (as diagnosed by event entailments and modifiers like frequent). $-e r^{\text {nonEv }}$ - nouns have non-eventive (dispositional or functional) readings.

b. Of-arguments are compatible with $-e r^{\mathrm{Ev}}$ but not $-e r^{\mathrm{nonEv}}$. Other -er-nominals (including compounds and argumentless nominals) can have either eventive or noneventive readings.

c. $-e r^{\mathrm{Ev}}$-nouns are sensitive to the argument structure of their parent verbs. They allow realization of internal arguments of $\mathrm{V}$, e.g. as of-phrases. Their referents correspond to $\mathrm{V}$ 's external (Initiator) argument in clauses.

d. $-e r^{\text {nonEv }}$-nouns are insensitive to V's argument structure. They disallow realization of (phrasal) arguments of $\mathrm{V}$. Their referents need not correspond to arguments of the parent verb and have no affinity with any particular thematic role.

instrument use of printer pre-empts the sense 'document to print'). For more on unified treatments, see Rainer (2013), Ryder (1999) and their references.

${ }^{4}$ Borer (2013) argues that eventive -er-nominals do not involve genuine argument realization. Her account can explain the Initiator interpretation of eventive -er-nouns, but leaves unclear why of-insertion arguments correspond closely to V's direct objects. 
Of course, equivalents of $-e r^{\mathrm{nonEv}}$ and $-e r^{\mathrm{Ev}}$ in other languages may have different properties. I illustrate some questions for future research with the web-attested French data in (11). Here non-event-entailing instrument nominals co-exist with phrases with de 'of' containing full DPs ( $d u$ is a suppletive variant of $d e+l e$ 'of the'), a constellation not foreseen in the taxonomy of French nominals in Roy \& Soare (2014). A salient illustration of the Anglo-French contrast is that (11)a) was translated on the same website with the compound Canadian retirement income calculator, while *calculator of Canadian retirement income is excluded on the intended instrument reading. Several hypotheses about such variation suggest themselves: (i) The Anglo-French contrast follows from some difference between de and of (despite many similarities in how they realize arguments in nominalizations, Knittel 2010). (ii) Unlike $-e r^{\text {nonEv }}$, the French affixes attach to phrasal constituents large enough to accommodate V's DP arguments. (iii) The French affixes are construed as Initiators of the related verbs, making them argument-structure-sensitive like $-e r^{\mathrm{Ev}}$, despite their non-eventive interpretation. I cannot choose between these hypotheses here, but they do illustrate some ways in which my approach might be reconciled with languages differing from English.
a. calculatrice du revenu de retraite canadienne calculator of.the revenue of retirement Canadian 'Canadian retirement income calculator'
b. compteur du nombre de visiteurs d'un site web counter of.the number of visitors of a website 'a device counting the number of visits to a website'
c. purificateur du système de l'injection de Diesel et de l'essence purifier of.the system of the injection of diesel and of the petrol 'a device that purifies the fuel injection system and petrol'

\subsection{Rejected accounts of the different types of -er-nominals}

We now describe problems with existing and imaginable accounts for the unavailability of ofinsertion with $-e r^{\text {nonEv }}$-nouns.

I see little hope for accounts assuming a semantic incompatibility between of-phrases and $-e^{\text {nonEv }}$-nouns. Alexiadou \& Schäfer (2010: 22-24; A\&S) argue that of-phrases must have a quantized interpretation which conflicts with the dispositional-generic semantics they propose for $-e r^{\text {nonEv }}$-nouns. However, of-phrases need not be quantized: mass and bare plural DPs are perfectly felicitous for instance in $-e r^{\mathrm{Ev}}$-nominals (a reader of novels/poetry), yet are still excluded in $-e r^{\mathrm{nonEv}}$-contexts (*electric washer of clothes). Furthermore, (12)a) shows that ofphrases (quantized or not) are not intrinsically event-entailing in event nominals, so the assumption that they must be intrinsically event-entailing in -er-nominals lacks independent motivation. A draft of A\&S proposed that specifically interpreted of-phrases would force event-entailing readings, contradicting the non-event-entailing semantics of $-e r^{\text {nonEv }}$-nouns. However, the underlined material in (12)b-c) is interpreted specifically, but compatible with a non-eventive dispositional/functional interpretation.

(12) a. Overlegislation includes the banning of very specific hypothetical actions, say the smoking of cannabis on pink bicycles or the waking of the current Lord Mayor with percussive piano playing.

b. He made an Osama bin Laden detector, but it was never used.

c. I made a long-handled hook for opening that particular window up there, but it's never been used.

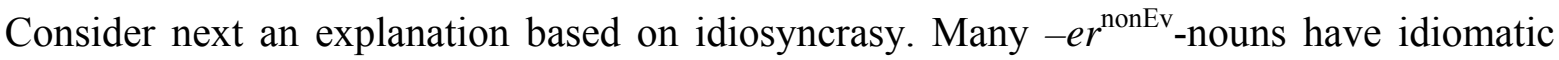
interpretations (plunger, bouncer, pacemaker, undertaker, lifesaver 'lifeguard', destroyer 
'military ship', pointer 'hint') but these are rare with $-e r^{\mathrm{Ev}}$-nouns ${ }^{5}$, and Randall's (1988:133) contrast photógrapher (*of insects) vs. phótographer of insects shows that $-e^{\text {nonEv }}$ is more prone to formal idiosyncrasy. One can imagine an argument that there is a heavy demand for conventional names for instruments and professions, meaning that the $-e r^{\text {nonEv }}$-nouns that name them will be memorized, and memorization cares little about semantic and formal regularity but favours short expressions like compounds over longer of-nominals. However, idiomaticity-based accounts will not give us enough mileage, as many $-e r^{\text {nonEv }}$-nominals are fully compositional (as L\&R note), and compositional $-e r^{\text {nonEv }}$-neologisms show the usual argument-structural constraints: I made a \{chess piece cleaner $/{ }^{*}$ cleaner of chess pieces\} but never used it.

Borer's (2003) account of non-argument-realizing zero nominals like a break (*of my leg) invokes the claim that they are nominalizations of category-neutral roots, not of verbs. This account is inapplicable to $-e r^{\text {nonEv }}$-nouns, since, as A\&S note, these tolerate bases with clearly verbal affixes like -ize and -en, (13). Roy \& Soare (2014: footnote 9) try to undermine this argument by appealing to semantic idiosyncrasies in some such nominals, but this completely undermines the empirical testability of the category-neutral root hypothesis. The fact remains that -ize and causative -en are unambiguously verb-forming affixes.

(13) organizer, vaporizer, tranquilizer, equalizer, sweetener, moistener, sharpener Van Hout \& Roeper (1998) capture eventiveness effects by claiming that $-r^{\mathrm{Ev}}$ selects TP, enabling the binding of V's event variable by T. By contrast, $-e r^{\text {nonEv }}$ selects only VP, which lacks the functional head licensing of-phrases, forcing V's object to incorporate. An objection is that $-e r^{\mathrm{Ev}}$-nominals eschew certain material found in normal TPs, say adverbs (*player of chess well); see also section 4. Attaching $-e r^{\text {nonEv }}$ to VP wrongly predicts PP complements with -er ${ }^{\text {nonEv }}$-nouns: this machine is a (glass) filler (*with water). This problem is solved if we attach $-e r^{\text {nonEv }}$ to a smaller constituent, $\mathrm{V}$, provided we can ensure that the nominalization does not inherit V's argument structure. Section 3 advances such an approach.

\subsection{Appendix: More on the interpretation of $-e r^{\text {nonEv }}$}

It is desirable (though not essential for my overall argument) to elaborate on the interpretation of $-e^{\mathrm{nonEv}}$-nouns. I will show that they may have either functional or (more marginally) dispositional interpretations, and that a unified description is problematic. My discussion draws on the taxonomy in (14).

(14) a. Humans in professional or similar functions: (maths) teacher, firefighter, dogcatcher, peacekeeper

b. Humans in temporary designated functions: minutes taker, present giver

c. Intrinsic-function entities: entities (often artifacts) construed as having the purpose of participating in the verbal event: printer, toaster, penholder, scraper; kneeler, locker

d. Incidental-function entities (entities designated for uses they were not designed for): I found a stone that looked like a good \{cutter/can crusher\}.

Alexiadou \& Schäfer (2010) suggest that $-e^{\text {nonEv }}$-nominals have dispositional interpretations: their referents are predisposed to participation in the verbal event-kind. Dispositional interpretations are independently needed for middles (the book reads well signals its predisposition for good reading) and it is intriguing that adjectives like good improve the acceptability of examples like (14)d), much as adverbs increase the acceptability of middles. The dispositional interpretation is plausible in (14)d). However, I will argue that nominals like (14)a-c) are not interpreted dispositionally, but functionally: they name entities whose

\footnotetext{
${ }^{5}$ An example of the latter is (frequent) lifesaver in an event-entailing hyperbolic sense 'thing/person that has metaphorically saved someone's life, i.e. got them out of significant difficulties'. Irrelevant here are $-e r^{\mathrm{Ev}}$-nouns based on idioms, e.g. (frequent) hackle raisers 'people who have raised hackles, i.e. annoyed people').
} 
designated or intrinsic function or purpose is to participate in the verbal event (cf. Levin \& Rappaport 1988).

Instruments like (14)c) have straightforward functional interpretations: printers are made to fulfil the function of printing. Reinterpreting printers dispositionally ('devices predisposed to printing') is an indirect semantic description which would be justified only if the dispositional reading were applicable to all other $-e r^{\text {nonEv }}$-nouns. That this condition is not met is seen, firstly, from animate nominals like (14)a,b). The non-event-entailing uses of e.g. (band)leader or law enforcer indicate that their referents have particular designated functions and say nothing about their aptitude (disposition) for these tasks. Dispositional readings can be imposed on such expressions by certain modifiers: born/potential leaders are predisposed to leadership without necessarily having exercised leadership functions. However, this does not hold of gifted/talented leaders, who must have had leadership roles. It thus appears that the functional interpretation is preferable to the dispositional one in describing (14)a,b). ${ }^{6}$

Some other -er-nouns have clearly non-functional, dispositional interpretations, but these are subject to lexicalisation and limited productivity. Widow makers as defined in (15)a) are predisposed to making widows, but this is not their function. Nevertheless this clearly dispositional interpretation does not generalize: a widow maker hanging over a children's playground cannot be called a (child) killer. Similarly, the referents of (15)b) have a possibly unrealized disposition for metaphorical heart-breaking/lady-killing, but parallel readings are unavailable for seducer, man hurter, heart winner. ${ }^{7}$ The examples in (15) also illustrate a tendency in which non-functional dispositional -er-nouns involve metaphoric, jocular, hyperbolic or otherwise metalinguistic language use. Finally consider pants shedder, which a speaker used in describing a rough slippery slide at a playground. This might look like a productively formed dispositional -er-noun (the slide is predisposed to shredding pants). However, this formation had a jocular tone, whose humor exploits the absurd concept of an artefact with the function of tearing pants. This makes sense if $-e r^{\text {nonEv }}$ is productive in the functional but not the dispositional use.

(15) a. widow maker 'branch that is dangerously liable to fall (forestry term)'

b. heartbreaker, lady killer

c. That guitar riff is a \{bone cruncher/baby killer/brain-melter\}.

Thus, a unified description of $-e r^{\text {nonEv }}$-nominals (say one which claims that they refer to entities which are deontically or epistemically expected to participate in the verbal event) would overgenerate: some $-e r^{\text {nonEv }}$-nominals only have functional readings while a smaller set only have dispositional readings. In section 3.1 we see that the two readings have a comparable distribution in nominal compounds.

\section{Blocking of-arguments with $-e r^{\text {nonEv }}$}

This section argues that constraints on argument-realization in $-e r^{\text {nonEv }}$-nominals reduce to similar problems seen with compounds: A device called a (guitar) tuner cannot be called a tuner of guitars for the same reasons that we can have (guitar) tuning device but not *tuning device of guitars. Section 3.1 sets the scene for this argument by showing that $-e^{\text {nonEv }}$ -

\footnotetext{
6 My position contrasts with that of Roy \& Soare (2014; R\&S), who propose a threefold classification of eventive, dispositional and instrument nominals. Their dispositional class, applied to English, includes nominals like consumer of drugs and user of skin cream which I class as eventive because they entail participation in actual events, not just a (possibly unrealized) predisposition to doing so, and because they allow of-phrases in English. R\&S's decision to classify these nominals as dispositional seems to have been motivated mainly by constraints on frequent-modification, but these data require clarification, structures like consommateur/utilisateur occasionel de cannabis 'occasional consumer/user of cannabis' being amply webattested.

${ }^{7}$ Dispositional readings are only possible here if coerced into existence by modifiers, cf. She was a born seducer, but never seduced anyone, or (ironically:) That branch over the sandpit is a wonderful child killer.
} 
nominals and compounds are grammatically alike in the relevant respects. Section 3.2 explains why (phrasal) arguments of compound nonheads and of $-e r^{\mathrm{nonEv}}$-nominals cannot be realized, while arguments of certain other morphological nonheads can. Section 3.3 shows that compounds like guitar tuner do not contradict this account.

\subsection{The compound-like interpretation of $-e r^{\text {nonEv }}$-nominals}

Preliminary demonstrations of the interpretational parallels between $-e r^{\text {nonEv }}$-nominals and compounds are given in (16)-(17). Here the primed -er-nominals have readings which are (near)-synonymous with the compounds on their left. Though such paraphrases are not always possible $^{8},(16)-(17)$ and many analogous cases suggest that functional interpretations are as well-established in compounds as in $-e r^{\text {nonEv }}$-nominals.

(16)
a. washing machine
b. wiping cloth
c. kneeling cushion
a'. washer
d. reading book
b'. wiper
c'. kneeler
e. cleaning lady
d'. reader
f. dressing cabinet
d'. cleaner
e'. dresser
a'. record cleaner
b. window cleaning fluid
b'. window cleaner
c. wire stripping tool
c'. wire stripper
d. pool cleaning device
d'. pool cleaner

(17) a. record cleaning cloth

Compounds parallel $-e r^{\text {nonEv }}$-nominals in disallowing eventiveness effects like frequentmodification and event entailments, and in disallowing of-complements, cf. (18)-(20) (where washer, kneeler and record cleaner are meant to have instrument interpretations like those of the compounds on their left).

(18) a. *frequent washing machine

b. *frequent record cleaning cloth

b'.*frequent washer

c. *frequent kneeling cushion

b'. *frequent record cleaner

c'*frequent kneeler

(19)

a. previously unused washing machines a'. previously unused washers

b. previously unused record cleaning cloths b'. previously unused record cleaners

c. previously unused kneeling cushions c'. previously unused kneelers

(20)

a. washing machine (*of clothes)

b. cleaning cloth $(*$ of records $)$

a'. washer (*of clothes)

c. kneeling cushion (*of/by worshipers) c'. kneeler (*of/by worshipers) ${ }^{9}$

$-e r^{\text {nonEv }}$ differs from normal compound heads in being a bound morpheme and in its highly underspecified semantics (it means 'entity' but additionally allows animate and mass interpretations, cf. teacher, fabric softener). However, these differences do not speak against a unified account of the argument-structural behaviour of $-e r^{\text {nonEv }}{ }^{-n o m i n a l s ~ a n d ~ c o m p o u n d s . ~}$

Another difference is that $-e r^{\text {nonEv }}$ has a selection restriction licensing its attachment to $\operatorname{verbs}^{10}$, whereas English [ $\left.\mathrm{N} \mathrm{VN}\right]$ compounding (washcloth, drawbridge, pushcart, scrubwoman, ${ }^{\%}$ scrub-brush) is far less productive than the $[\mathrm{N}[\mathrm{N}$ Ving $] \mathrm{N}]$ compounding

\footnotetext{
${ }^{8}$ Often for irrelevant reasons: toasting appliance suggests an unusual toasting device by implicature, there being no reason to bypass the short, entrenched term toaster in referring to normal toasting devices. Likewise we do not expect baking/teaching man in lieu of baker/teacher, except perhaps under whatever conditions yield classifier doublings of the type fisherman, baker man, preacher dude.

${ }^{9}$ In the $\{k n e e l i n g$ cushion/kneeler\} of Mary the of-phrase is a possessor, not an agent of kneel, since the expression says nothing about whether she might kneel on it.

${ }^{10}$ er- unambiguously attaches to verbs in (13). I see no evidence that it attaches to category-neutral roots. Denominal formations like falconer, executioner also exist (Ryder 1999), but I doubt the empirical feasibility of unifying denominal and deverbal -er, for instance because new formations like DMer 'Distributed Morphology practitioner', roofer 'ball that hits the roof' have a colloquial flavour missing in deverbal formations.
} 
witnessed in (16)/(17). To create a structure interpreted like an $-e r^{\text {nonEv }}$-nominal but with a regular noun as head, $\mathrm{V}$ must first be nominalized to allow it to undergo productive NN compounding. In the resulting $[\mathrm{N}[\mathrm{N}$ Ving] $\mathrm{N}]$ structures, -ing is semantically vacuous. It does not interfere with the semantic parallels in $(16) /(17)$, and many [N Ving]N] compounds translate with German [N VN] compounds (Waschmaschine 'wash ${ }_{\mathrm{V}}$-machine', Schuhputztuch 'shoe-clean ${ }_{V}$-cloth'; see Gast (2008)).

Compounds mirror the generalization in section 2.3 that functional interpretations of $-e r^{\text {nonEv }}$-nouns are more productive than dispositional ones. Compounds allowing nonfunctional dispositional readings seem rare. Examples are collision course 'trajectory predisposed to cause collision', cutgrass 'type of grass predisposed for cutting' and húmming bird (relevant if the stress diagnoses this as a NN compound and not an AN structure like praying mántis). By contrast, many compounds like those in (16)-(17) have clear functional interpretations. A neologism like plate breaking machine is forced to have a pragmatically implausible functional interpretation 'machine made for plate breaking', even when used in irony or jest of a faulty dishwasher liable to break plates. This is unexpected if compounds freely allow dispositional interpretations. ${ }^{11}$

\subsection{The Morphological Nonhead Constraint}

The discussion in section 3.1 of similarities between $-e r^{\text {nonEv }}$-nouns and compounds was a first step towards the task of this section, which is to reduce the ban on of-arguments with $-e r^{\text {nonEv }}$ nouns (*computerized washer of clothes) to factors blocking of-arguments with compounds (*washing machine of clothes). I treat both as instances of the descriptive generalization in (21) (a descendent of claims about compounds in Di Sciullo \& Williams (1987:30), Ackema \& Neeleman (2004:26)).

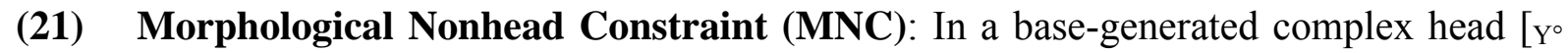
$\mathrm{XY}]$, X's arguments cannot be realized outside [ $\left.\mathrm{Y}^{\circ} \mathrm{XY}\right]$ in the default case.

Here "base-generated complex head" is any complex head formed by direct merger and not by head movement. It makes sense to exclude head movement derivations from (21), as such derivations are normally meant to allow argument realization rather than blocking it: a head combines with an argument, then moves to a higher head to form a complex head, cf. (4)a).

I will explain (21) with reference to the base-generated complex head structures in (22), which are standard in lexicalist work (say Ackema \& Neeleman 2004, Lieber 2004) and which I assume here (though taking no stand on whether they are generated presyntactically or in syntax). By assumption $-e r^{\mathrm{nonEv}}$ in (22)a) and the variant of -ing in (22)b) select $\mathrm{V}^{\circ}$ constituents. These selection restrictions are violated if the nonheads merge with phrasal arguments: *[vp wash the clothes]-er/-machine. Phrasal arguments could be realized if the mechanism sometimes called 'percolation' allowed them to be merged at a distance from the heads selecting them (recall the discussion of (4)b)). However, (21) states that such mechanisms are not posited by speakers, at least not as a general option. ${ }^{12}$ The latter

\footnotetext{
11 The functional interpretation of many compounds is supported by their allowing for-paraphrases expressing the function of the head noun (cup breaking machine = machine for breaking cups, kneeling cushion = cushion for kneeling on, and similarly with most examples in (16)-(17)). For-relations have been identified as an important possible interpretation of compounds (Spalding \& Gagné 2011), and are expressed overtly in French compounds like machine à laver ('machine for washing, i.e. washing machine').

${ }^{12}$ This is just as well since unconstrained long-distance realization of arguments of nonheads would, like a syntax without locality constraints, cause intolerable ambiguities. Interpreting (i) and (ii) would involve deciding whether the of-phrase belongs to the head or the nonhead, and the difficulties multiply in recursive structures like (iii).

(i) head movement of complex verbs ( $\neq$ 'movement of heads of complex verbs')

(ii) the friendliness of Ann ( $\neq$ 'quality of being a friend of Ann')

(iii) the impeachment proposal response drafting committee of the ministers
} 
qualification is needed because section 3.2.2 argues that $-e r^{\mathrm{Ev}}$-nominals like reader of the book override the default in (21), for principled reasons.
a. $\left[\mathrm{N}^{\circ} \quad\left[\mathrm{v}^{\circ}\right.\right.$ wash $]$
$\left.\left[\mathrm{N}^{\circ}-e r^{\mathrm{nonEv}}\right]\right]$
(*of clothes)
b. $\left[\mathrm{N}^{\circ}\left[\mathrm{N}^{\circ}\left[\mathrm{v}^{\circ}\right.\right.\right.$ wash $]$ ing $]$
[Nomachine $]]$
(*of clothes)

(21) holds of arguments other than of-phrases, for instance PP complements (*reliance problem on drugs). (21) also limits the possible analyses for compounds like lawnmower. If these have the structure [N [N lawn][N mower]], then (21) forces us to deny that lawn realizes an argument of mow. By contrast (21) does not forbid nonheads from realizing arguments inside complex heads in structures like [N [v lawn-mow]-er]. Section 3.3 shows that the predictions regarding compounds are correct.

More is said on why (21) holds in section 3.2.3, but I must firstly discuss its empirical correctness in the face of apparent and real exceptions.

\subsubsection{Nominal compounds apparently violating the MNC}

In contrast to what is seen in many cases like *cleaning lady of offices, *stripping tool of wire, *drag chain of/by back vowels, the internet attestations in (23) feature optional ofphrases which might be analyzed as arguments of compound nonheads. (See FabriciusHansen (1993) on related German data.)

(23) a. ${ }^{\%}$ the name choice of my child

"choice of my child's name")

b. " the destruction plans of Dresden ("plans of the destruction of Dresden")

c. ${ }^{\%}$ location hypotheses of Atlantis

d. ${ }^{\circ}$ a word in first sister position of the verb (Roeper \& Siegel 1978:208)

e. i. the daughter languages of Latin

ii. the ancestor language of nearly all European languages

iii. the ancestral language of a good many of today's languages.

The MNC in (21) could be maintained if speakers accepting (23)a-d) form the compounds by head movement, which is standardly taken to allow complement stranding: [NP name choice [NP $t_{\text {name }}$ of my child]]. However, deriving the adjective-noun string in (23)e iii) by head movement would be dubious, e.g. since the of-phrase is not a plausible argument of ancestral: * Latin is ancestral of Catalan.

I suggest that the of-phrases in (23) are not realizers of arguments of compound nonheads but possessive genitives licensed by the relational semantics of the whole compound. This is clearest in (23)e). Compounds like daughter languages and A-N complexes like ancestral language are relational in that they entail the existence of other languages, parallel to the similarly interpreted simplex relational nouns ancestor/descendent (of Latin). Like other relational expressions, the related entities can also appear in other possessive contexts (Latin has several daughter languages), a flexibility not witnessed when of is a realizer of an inherited argument (the destruction of Carthage vs. *Carthage had an awful destruction).

Relational interpretations for the compounds in (23)a-d) are harder to establish, accounting for their more marginal status. (23)d) seems better than (a-c), understandably since the ofphrase is plausibly a possessor, witness verbs have only one first sister position. (23)a) works best when choice has a result interpretation, making name choice exchangeable with the relational noun name ('Marmaduke' was an unfortunate name (choice)). (23)b,c) are more marginal than the others, correlating with the greater difficulty in finding contexts independently confirming that the compounds can have possessors. However, such contexts do exist: The Allies had planned the destruction of several German cities, but until 1944 Dresden had no destruction plans.

It thus seems plausible to treat of-phrases like those in (23) as genitives licensed by the relational semantics of the whole compounds. If there were a mechanism which allowed arguments of compound nonheads to be realized compound-externally, one wonders why it is 
unavailable in cases like scrub brush (*of floors), filling pump (*with water), cleaning cloth (*of records) and many other cases.

\subsubsection{Genuine MNC violations: Argument-structure-sensitive affixes}

Section 4.2 will argue that some $-e r^{\mathrm{Ev}}$-nominals have lexicalist-inspired derivations like (24), where the complex head is created by base generation, not head movement, and an argument of $\mathrm{V}$ is realized after affixation. Assuming that $\mathrm{V}$ is not the head of the nominal, this derivation is a genuine exception to the MNC in (21).

(24) $\left[\mathrm{NP}\left[\mathrm{N}^{\circ}\left[\mathrm{v}^{\circ}\right.\right.\right.$ read $\left.]-e r^{\mathrm{Ev}}\right]$ of novels $]$

Why are such MNC-violating derivations permitted with $-e r^{\mathrm{Ev}}$ but not with $-e r^{\text {nonEv }}$ and compounds? Lexicalist studies assuming derivations like (24) have apparently not attempted principled answers to this question. Ackema \& Neeleman (2004:27) stipulate that -er has an optional argument which is identified with an argument of the affixed verb. A more detailed account along these lines would assume that $-e r^{\mathrm{Ev}}$ has such an argument but $-e r^{\mathrm{nonEv}}$ does not, so we find of-phrases in (24) but not in *electric opener of bottles. It is unclear how this could explain why a given affix (dis)allows argument inheritance (given the problems with semantic explanations seen in section 2.2). Ideally the possibility of inheritance should follow from a property of $-e r^{\mathrm{Ev}}$ other than its observed compatibility with of-phrases. I propose that this property is that $-e r^{\mathrm{Ev}}$ and other inheritance-licensing affixes are argument-realizers or otherwise sensitive to argument-structural features of their bases. The argument-structuresensitivity of $-e r^{\mathrm{Ev}}$ manifests itself in the observation in section 2.1 that $-e r^{\mathrm{Ev}}$-nominals always correspond to Initiators of their parent verbs. If one assumes that Initiators are arguments of $\mathrm{V}$, and if $-e r^{\mathrm{Ev}}$ realizes an Initiator argument (cf. Ackema \& Neeleman 2004:27), then $-e r^{\mathrm{Ev}}$ could only attach to a $\mathrm{V}$ whose argument structure is active, i.e. has not been suppressed in some way. Since V's argument structure is active, then any other arguments of V must also be realized. Since the relevant variant of $-e r^{\mathrm{Ev}}$ selects $\mathrm{V}^{\circ}$, DP arguments cannot be realized inside $\left[\mathrm{N}^{\circ} \mathrm{V}^{\circ}-e r^{\mathrm{Ev}}\right]$, but can be realized outside it using the of-insertion mechanism available in English DPs. ${ }^{13}$

It is actually debatable whether the derivations just described are true instances of the inheritance of arguments of nonheads banned by the $\mathrm{MNC}$, since $-e r^{\mathrm{Ev}}$-nominals exhibit a sort of ambiguous headship. Certainly, -er is the category-determining head and the semantic head (the nominals name types of entities, not events). However, normally expressions merging with their arguments are heads of the resulting constituents, and $-e r^{\mathrm{Ev}}$ realizes an argument of $\mathrm{V}$, making $\mathrm{V}$ the argument-structural head of the nominal. $\mathrm{V}$ is also head of the nominal under Collins' (2002) definition of heads as elements with unsatisfied features. Precedents for dual headship include Di Sciullo \& Williams' (1987:26) notion of relativized headship and Hudson's (2004) evidence that both N and D act as heads of nominal projections. While my concept of dual headship is in its infancy, this perspective makes it less surprising that $-e r^{\mathrm{Ev}}$ nominals exhibit a kind of complex predicate behavior in which a morphological nonhead is allowed to bequeath an argument to the complex head.

\footnotetext{
${ }^{13}$ If one accepts (as I do, though not crucially here) that Initiators in clauses are introduced by heads like Voice and not by V (e.g. Kratzer 1996), then $-e r^{\mathrm{Ev}}$ in (24) would be a nominal Voice head whose referent is an Initiator (cf. Baker \& Vinokurova 2009:520, 532; Bowers 2011:1200). My account entails that Voice is sensitive to an argument-structural feature on V, call it [+Initiator]. This claim has a precedent in Bowers $(2011: 1195)$. It is also eminently reasonable. Voice does not add an Initiator interpretation to V's meaning, as is clear with verbs like read, massage, discuss which cannot be conceptualized and defined without reference to Agents (which are therefore obligatory with such verbs, cf. Levin \& Rappaport Hovav 1995:102). Voice is thus unlike optional devices (whether lexical rules, applicative heads or silent prepositions) which add arguments not present in V's basic meaning, say beneficiaries (burn me $a c d$ ) or locations (work the bars). Thus, the role of Voice is comparable to the role of to in hand books to children: both are devices which enable the syntactic realization of arguments of $\mathrm{V}$, guaranteeing their thematic interpretation (respectively as Initiators and Recipients).
} 
The factors allowing argument inheritance with $-e r^{\mathrm{Ev}}$ are absent with $-e r^{\mathrm{nonEv}}$. The latter does not realize an argument of $\mathrm{V}$, as shown in the discussion of (8). Consequently, $\mathrm{V}$ is in no sense the argument-structural head of $\left[\mathrm{N}^{\circ} \mathrm{V}-e r^{\mathrm{nonEv}}\right]$, and $-e r^{\mathrm{nonEv}}$ is compatible with a $\mathrm{V}$ with an inactive argument structure.

Another illustration of the analysis applied to $-e r^{\mathrm{Ev}}$ would be adjectival passives, if any of them have a base-generated complex head structure like (25). Adjectival passives always predicate over arguments corresponding to V's direct object, so V's argument structure is active. Even on the common view that Initiators are not realized in adjectival passives, adjectival passive is still sensitive to Initiators since part of its job is to suppress them (Levin \& Rappaport 1986) or equivalently to act as a defective Voice head (McIntyre 2013). McIntyre (2013) argues in detail that adjectival passive is specifically an Initiator-suppressing operation distinct from the less productive operation yielding unaccusative-based participles (departed/*gone/*fled guests).

(25) $\left[\mathrm{A}^{\circ}\right.$ un- $\left[\mathrm{A}^{\circ}\left[\mathrm{V}^{\circ}\right.\right.$ train $\left.\left.]-e d\right]\right]$ people

\subsubsection{Summary and further discussion of the MNC}

Thus far in section 3.2, I have argued for the MNC in (26) (which revises (21) to include findings in section 3.2.2).

(26) Morphological Nonhead Constraint (MNC): In a base-generated complex head $\left[\mathrm{Y}^{\circ}\right.$ $\mathrm{XY}]$, X's arguments cannot be realized outside [ $\left.\mathrm{Y}^{\circ} \mathrm{XY}\right]$, unless $Y$ realizes an argument of $X$ or is otherwise sensitive to $X$ 's argument structure.

The MNC entails that there is no generally available mechanism of percolation which allows arguments of nonheads to become arguments of the whole complex head, or otherwise to be realized at a distance from the nonhead. The italicized portion of (26) was argued in section 3.2.2 to be a principled exception, in that the attachment of argument-realizing affixes like $-e r^{\mathrm{Ev}}$ requires V's argument-structural features to be active, which means that any other arguments of $\mathrm{V}$ must also be realized. $-e r^{\mathrm{nonEv}}$ is not argument-structure-sensitive and is thus beyond the remit of the italicized condition in (26).

We now elaborate on the nature of the MNC and the reasons for its existence. A necessary condition for $\mathrm{MNC}$ effects is an environment where an $\mathrm{X}^{\circ}$ element is selected as a morphological nonhead by a (non-argument-structure-sensitive) affix or compounding rule. This greatly curtails the options for realizing the nonhead's arguments. Let us illustrate this with the $-e r^{\text {nonEv }}$-nominal poker (*of fires) (*by adults). The parent verb poke has two obligatory arguments in clauses (I poked the fire $/ *$ The fire poked $/ *$ I poked). These arguments must normally be housed in phrasal projections, say VoiceP (or S in some theories). However, such projections are larger than the $\mathrm{V}^{\circ}$ selected by $-e^{\mathrm{nonEv}}$, witness $* a$ children-poke-fires-er 'thing for children to poke fires with'. Moreover, (26) assumes that speakers simply do not consider long-distance realization of poke's arguments outside poker to be an option. There is thus no way to realize phrasal arguments of $\mathrm{V}$ in poker ${ }^{\mathrm{nonEv}}$. (26) is in principle compatible with incorporated arguments in structures like [ $\mathrm{N}_{\mathrm{v}} \mathrm{v}$ fire pok]-er], but here the status of fire as an argument of poke is debatable (section 3.3).

An under-asked question is why the non-realization of obligatory arguments of $\mathrm{V}$ in nominals like poker ${ }^{\text {nonEv }}$ does not yield ungrammaticality. One might have expected $-e r^{\text {nonEv }}$ to be compatible only with verbs lacking obligatory internal arguments, but poker, overseer, destroyer, moisturiser, among others, have argumentless $-e r^{\text {nonEv }}$-uses formed from obligatorily transitive verbs. In fact, one might have expected $-e r^{\text {nonEv }}$ to be incompatible with verbs that select any obligatory arguments, including Initiators, but this expectation also goes unfulfilled: otherwise obligatory Initiator arguments remain unrealized in instrument or location nominals like poker, kneeler, scraper and, as argued in section 2.1, even in $-e^{\mathrm{nonEv}}$ nominals which happen to correspond to V's Initiator (lifesaver, teacher). This problem is not fully solved if we treat Agents with poke, kneel, scrape as arguments of Voice rather than V, 
and assume that $-e r^{\text {nonEv }}$ cannot select Voice projections. This begs the question as to why the Agent-licensing Voice head is obligatory in clauses but not in $-e r^{\text {nonEv }}$-nominals. Analogous questions remain unanswered in theories in which Patients/Themes as well as Initiators are introduced by functional heads (Borer 2003, 2013; Bowers 2011).

These considerations lead me to suggest that adding non-argument-structure-sensitive $\mathrm{V}^{\circ}$ selecting affixes like $-e r^{\text {nonEv }}$ is a coercive act which disregards the argument structure of the nonhead V. This coercion could take the form of an operation (call it SUPPRESS) which deactivates the argument-structural features of the nonhead. Landau's (2009) Saturation operator is a precedent for this in another domain. Like Landau, I assume that the operation deactivates all argument-structural features of the head targeted, rather than eliminating specific arguments (as occurs in many lexical rules, say the external-argument-suppressing adjectival passive rule in Levin \& Rappaport 1986). SUPPRESS as used here is a last resort which is called upon to prevent a nonhead from projecting structure which would violate the morphological selection restrictions of the affix selecting it. In clauses these triggering conditions are absent, so we do not generate sentences like *[тр There died].

\subsection{Synthetic compounds: the analysis of record cleaner}

Section 3.2.3 proposed that when $-e^{\text {nonEv }}$ is attached, V's argument selection features are cancelled by the SUPPRESS operation, making further argument realization impossible. This analysis would be refuted if the nonheads of synthetic compounds like record cleaner, lifesaver are grammatically represented as arguments of the affixed verbs and are merged after $-e r^{\text {nonEv }}$ as in (27)a). I will show that this kind of argument structure percolation is unnecessary and problematic.

(27) a. [No record [ $\mathrm{N}^{\circ}$ cleaner]]

b. [ $\mathrm{N}^{\circ}\left[\mathrm{v}^{\circ}\right.$ record clean $\left.\left.]-\mathrm{er}\right]\right]$

My proposal in section 3.2 can be maintained if compound nonheads combine with $\mathrm{V}$ before $-e r^{\text {nonEv }}$ does (and before SUPPRESS applies), as is possible in the structure in (27)b). This compounding-before-affixation approach has its proponents (e.g. Ackema \& Neeleman 2004:56-66; Borer 2013; Harley 2008). Other linguists (e.g. Lieber 2004:48f) reject (27)b) since it posits NV-constituents which often cannot appear independently (*I record-cleaned). This does not refute (27)b) since there are less controversial morphological constituents which cannot appear independently, e.g. in half-hearted (*hearted, *half-heart), and analogously in two-line answer, two-seater, specifier-head-complement order.

Moreover, developing arguments in Borer (2013) and Ackema \& Neeleman (2004), we can support (27)b) using data like (28)/(29). Here we find idiomatic interpretations which occur in compounds of the form [ $\mathrm{N} \mathrm{NVer}$ ] as well as [ ${ }_{\mathrm{N}} \mathrm{NVing}$ ] and/or [ $\mathrm{A}$ NVing], although there are no corresponding overtly usable $[\mathrm{v} \mathrm{VN}]$ forms or VPs. Unless the existence of these idiomatic interpretations with both -er and -ing is coincidental (which is unlikely since the nominals in (30) appear in similar paradigms), we must posit [v VN] constituents like self-seek $\mathrm{V}_{\mathrm{V}}$ 'be selfish' which are bound, i.e. lack corresponding overt noun-incorporation verbs like (28)b). Thus, for these compounds the structure in (27)b) is preferable, and I see no reason why it should not be equally applicable to compositional compounds like record cleaner.

(28) a. self-seeker / self-seeking ${ }_{\mathrm{N} / \mathrm{A}}$ 'egotist/selfishness/selfish'

b. *they self-seek

c. *they seek themselves / *the seeking of oneself

(29) a. crystal gazer/gazing ('fortune teller/telling')

(Borer 2013)

b. * to crystal-gaze

c. ${ }^{\#}$ to gaze at crystals / ${ }^{\#}$ this gazing at crystals (non-idiomatic) 
world-beater, gender-bender, market maker, house-warmer, blood-letter, bookmaker ('betting agent'), pen-pusher ('bureaucrat'), tree-hugger ('hippie'), housebreaker ('burglar'), watchmaker ('watch repairer')

That [ $\mathrm{N}^{\circ}$ [ $\mathrm{v}^{\circ}$ record clean]-er]] exists does not entail that [ $\mathrm{N}^{\circ}$ record [ $\mathrm{N}^{\circ}$ cleaner]] cannot exist. The latter resembles record brush in that both instantiate productive NN compounding with analogous interpretations ('brush/cleaner for records'). This interpretation of [ $\mathrm{N}^{\circ}$ record $\left[\mathrm{N}^{\circ}\right.$ cleaner]] does not treat record as an inherited argument of clean and is thus compatible with my proposal in section 3.2. This proposal is only incompatible with the structure [ $\mathrm{N}^{\circ}$ record $\left[\mathrm{N}^{\circ}\right.$ cleaner]] if record is grammatically represented as an argument of clean.

More evidence for my position comes from (31). Here of-phrases are excluded, instantiating the generalization that English zero nominalizations disallow realization of V's arguments (Borer 2003, Grimshaw 1990). However, compound nonheads are possible with these nominals, suggesting either that they are not real arguments of $\mathrm{V}$, or that they merge before zero nominalization renders V's argument structure inactive. If compound nonheads were arguments of $\mathrm{V}$ that merge after nominalization, we would wrongly expect argument realization by of-phrases in (31). ${ }^{14}$

(31) a. a typologically rare kind of \{topic drop/*drop of topics\}

b. this $\{$ heartbreak/*break of my heart/bloodshed/*shed of his blood/stock split/*split of a $\$ 900$ stock/witchhunt/*hunt of alleged witches/haircut/*cut of his hair\}

c. His $\left\{{ }^{\%}\right.$ drug pushes $/ *$ pushes of nefarious drugs $\}$ got him arrested.

d. those $\{$ dummy-spits/*spits of the dummy (cf. spit the dummy 'throw a tantrum')

I lack the space for further discussion of compounds, but hope to have shown that an MNCviolating analysis in which compound nonheads realize arguments of $\mathrm{V}$ in a configuration $\left[\mathrm{N}\left[\mathrm{N}^{\circ} \mathrm{V}-e r^{\mathrm{nonEv}}\right]\right]$ is more problematic than the alternative MNC-compatible analyses.

\section{$4-e r^{\mathrm{Ev}}$-nominals}

I now turn to $-e r^{\mathrm{Ev}}$-nominals, arguing that at least some of them are subject to argumentstructural constraints which follow naturally only given lexicalist-style derivations where $-e r^{\mathrm{Ev}}$ selects $\mathrm{V}^{\circ}$ and $\mathrm{V}$ 's arguments are inserted outside the complex $\mathrm{N}$. This claim contrasts with the non-lexicalist tendency to explain argument inheritance in terms of head movement. (32) illustrates variants of this approach to $-e r^{\mathrm{Ev}}$-nominals, for perspicuity ignoring head movement of the verb/root read to -er and simplifying some approaches in the literature. In (32)a), -er is a type of Voice/ $v$ head which expresses a property of an Initiator (cf. Baker \& Vinokurova 2009:520, 532). The inherited DP argument is licensed inside VP, with of inserted for Case reasons by some mechanism. In the variant in (32)b), -er selects a VoiceP with an unpronounced Initiator, labeled x. -er binds this argument (cf. Alexiadou \& Schäfer 2010:14f). Further variation between head movement accounts concerns the treatment of ofinsertion. (32)c) differs from (32)a,b) in that of-arguments are licensed as specifiers of a functional category (cf. van Hout \& Roeper 1998). - er selects different phrasal projections in different approaches. Apart from VP or VoiceP, these include projections of category-neutral roots (Harley 2008) and TP (van Hout \& Roeper 1998).

a. [NP -er [vP read [DP/PP (of) the book]]]

b. [NP -er [VoiceP X [v, Voice ... [vp read [DP/PP (of) the book]]]]]

c. [XP X [YP [DP/PP (of) the book] Y [NP -er [vp read the book]]]]

All head movement approaches assume that $-e r^{\mathrm{EV}}$ selects a VP or other projection containing $\mathrm{V}$ and its internal arguments. I will argue that this overgenerates for at least some English speakers. The relevant data are introduced now.

\footnotetext{
${ }^{14}$ This argument is indirectly inspired by arguments in Ackema \& Neeleman (2004:56) and Borer (2013:ch.12), which however invoke the debatable judgment that of-nominals like the breaker/breaking of the ice lack the idiomatic interpretation of compounds like icebreaker/icebreaking.
} 


\subsection{Argument realizability with $-e r^{\mathrm{Ev}}$-nominals}

While internal DP arguments of monotransitive verbs can be freely realized as of-phrases in $-e r^{\mathrm{Ev}}$-nominalizations (buyers/admirers of the book), the realization of other kinds of arguments with $-e r^{\mathrm{Ev}}$ is subject to constraints that have had very little attention beyond the brief discussions in Randall (1988) and Grimshaw (1990). I will now offer a more detailed empirical description.

Clausal complements have been assumed to be incompatible with -er-nominals (Grimshaw 1990:101f). This is echoed in my judgments in (33). However, such restrictive judgments contrast with the judgments of liberal speakers, who accept clausal arguments with -ernominals, cf. the internet attestations in (34). Five of nine native speakers I surveyed gave liberal judgments, while four rejected structures like (34). ${ }^{15,}{ }^{16}$ Head movement approaches like (32) do not predict restrictive judgments like (33), since they posit phrasal projections which should be able to house clausal complements.

a. *the discoverer [ $\mathrm{CP}$ that the world is round]

b. LIKE (a): observer, doubter, denier, pretender, revealer, preacher, thinker, proclaimer, complainer, boaster

c. *a pretender/aspirer/tryer/hoper to change the system

d. *an instructor/advisor of people to obey orders

e. *the causer/orderer of these people to be killed

(34) a. ${ }^{(*)}$ a firm believer that knowledge is power

b. ${ }^{(*)}$ the first discoverer that sound can be transmitted by an electrical current

c. ${ }^{(*)}$ a proponent that people should be compelled to ID themselves

AP resultative and depictive predicates were rejected by five of nine informants (four of whom also rejected clausal complements with -er-nominals):

(35) a. ${ }^{(*)}$ She is a habitual \{painter of walls white/hammerer of metal flat\}.

b. ${ }^{(*)}$ The English are habitual drinkers of beer warm.

AP predicates with causative light verbs like (36)a) were rejected by eight of my nine consultants. However, I concede that head movement approaches may be able to handle this by reducing it to whatever causes the ban on of-insertion with arguments not thematically licensed by $\mathrm{V}$ in contexts like (36)b,c).

(36) a. ${ }^{*}$ Ignorant purism is a \{maker sick of linguists/maker of linguists sick\}.

b. * the making \{sick of linguists/of linguists sick\}

c. *the considering/consideration of John honest

Double object constructions and predicative DP constructions in -er-nominals are rejected by all speakers, cf. (37), but again I concede that their unacceptability may be due to factors not intrinsically incompatible with head movement analyses, including a possible ban on multiple of-insertion (Borer 2013), the ban on of-insertion with ECM structures in (37)b), or the incompatibility of -er with silent morphemes sometimes posited in double object constructions (applicative heads, silent prepositions).
a. *a giver (of) children (of) presents; *a baker (of) people (of) cakes
b. *a caller (of) people (of) names; *the caller of John (of) a moron

\footnotetext{
${ }^{15}$ I reject all clausal complements in (33) and (34), except with believer with deontic (believed-in) propositions, cf. my judgments in (i) and (ii). Possibly the CP in (i) is embedded under an unpronounced in, making (i) an instance of PP inheritance, which $-e r^{\mathrm{Ev}}$ tolerates more readily (see below).

(i) 'believers that discipline is good (=believers in discipline)

(ii) "believers that Oswald shot Kennedy (=? ?believers in the lone assassin theory)

${ }^{16}$ A study of judgments of nine consultants says nothing about the relative commonness of the two types of judgments and about their geographical and sociolinguistic distribution. However, this modest sampling suffices here, since I aim only to confirm the existence of restrictive speakers and to propose a grammar for $-e^{\mathrm{EV}}$ in their idiolects.
} 
Adverbs in -er-nominals are rejected by all speakers, cf. (38). ${ }^{17}$ Baker \& Vinokurova (2009) argue that this generalization holds crosslinguistically, and their explanation for it is compatible with head movement approaches. They argue that adverbs cannot merge below -er since by assumption adverbs never merge below Agent-introducing heads. Adverbs cannot merge above -er since it nominalizes the structure, disqualifying it from adverbial modification. (Event nominalizers are not intrinsically constrained in this way, and indeed some of them clearly operate over larger verbal projections: his not having read the book carefully.) An imaginable alternative account would be that there is a crosslinguistic ban on attaching agentive affixes (or participant-naming affixes) to constituents larger than $\mathrm{V}^{\circ}$, but it is hard to see why this should hold. I will therefore accept the Baker-Vinokurova account.

(38) builders (of houses) (*skilfully/*well), *a worder of contracts carefully

PP arguments in $-e r^{\mathrm{Ev}}$-nominals differ in their acceptability. (39) gives internet-attested examples which I find perfect despite being a restrictive speaker. Five of nine informants I consulted accepted (39)c,d). By contrast, examples like (40)a,b) are strongly degraded to me and my informants (despite internet attestations of (40)b)). Randall (1988:134f) provides further unacceptable examples of inherited PPs, including (40)c,d). ${ }^{18}$

(39) a. believers in evolution, contributors to books, spongers off the state, sufferers from gout, a railer against religion

b. the largest importer of goods into the US, a giver of gifts to poor children, a driver of trucks to Zambia, protectors of people from harm

c. separators of the wheat from the chaff

d. a legendary drinker of people under the table

(40) a. *a beater of people to death, *the breaker of the vase to bits

b. ${ }^{*}$ lookers at pictures, ${ }^{(*)}$ talkers about inflation

c. *A nurse is more than just a hander of scalpels to surgeons.

d. *The volunteer office needs a paster of stamps onto envelopes.

I cannot fully explain the contrast between (39) and (40). The contrast between resultatives like (39)d) and (40)a) seems particularly puzzling, since nominalizations of unselected object resultatives like (39)d) are normally less acceptable than those of resultatives obeying V's normal selection restrictions (cf. the judgments of -ing-nominalized resultatives in Carrier \& Randall 1992). Some PPs might be more acceptable because they are independently usable with underived nominals (believer/faith in science, traveller/passenger to Spain, a giver/present to children) but this cannot explain (39)c,d). Analyzing the acceptable PPs as modifiers rather than inherited arguments is implausible with idiosyncratically selected prepositions (believers in evolution) and obligatory PPs (railers against religion vs. they constantly rail *(against religion)).

Thus, PP arguments can be inherited in $-e r^{\mathrm{Ev}}$-nominals in all idiolects, but are subject to constraints which remain to be identified. Whatever the nature of these constraints, they are not expected in head movement approaches, which posit (extended) verbal projections which allow enough space to accommodate PPs. Such constraints are less surprising in theories

\footnotetext{
17 A rare, speaker-specific kind of exception I found is (i). It is unclear if these adverbs really modify the nominalized verbs, since the same adverbs modify underived nouns in attestations like (ii)-(iii) and the imaginable book title Adverbs Crosslinguistically. Possibly such adverbs modify elliptical material (providers of quality goods operating globally; Adverbs Viewed Crosslinguistically).

(i) $\quad{ }^{\circ}$ providers of quality goods \{globally/internationally/worldwide\}

(ii) ${ }^{\%}$ its nomination for "Best Private Bank Internationally for Innovative Products and Services"

(iii) $\quad \%$.... a guest internationally on a number of radio and television talk shows...

${ }^{18}$ Randall's claim that -er-nominals allow maximally one inherited argument seems overstated in view of (39)bd), and some data like * a putter of books on shelves might be excluded by whatever factors exclude of-insertion with arguments which are not thematic arguments of $\mathrm{V}$, cf. (36).
} 
where inherited PP arguments merge after nominalization, since factors like incompatibility with nouns or constraints on argument percolation could interfere with argument linking.

I conclude from this section that English speakers may have one of two variants of $-e r^{\mathrm{Ev}}$ : $\boldsymbol{e r}^{\text {Ev.liberal }}$ which is compatible with clausal and AP arguments and $-\boldsymbol{e r}{ }^{\text {Ev.restr(ictive) }}$, which is not. The behavior of $-e r^{\mathrm{Ev} . r e s t r}$ is unexpected in head movement accounts like (32), since these accounts posit VPs or other extended verbal projections which should be able to house clausal and AP arguments. Section 4.2 offers a more adequate analysis for $-e r^{\text {Ev.restr }}$. Here I will not focus on $-e r^{\text {Ev.liberal }}$-nominals. I concede that they might have head movement derivations, although head movement accounts must explain why $-e r^{\text {Ev.liberal }}$ is incompatibile with adverbs, double objects, ECM structures and certain PPs. The constraints on PPs seem particularly hard to explain in such accounts. ${ }^{19}$

\subsection{The grammar of $-e r^{\text {Ev.restr }}$-nominals}

I now give an analysis of $-e r^{\text {Ev.restr }}$ which predicts its incompatibility with clausal and AP arguments. The idea is that $-e r^{\text {Ev.restr }}$ combines with $\mathrm{V}^{\circ}$, with arguments of $\mathrm{V}$ merged after nominalization as arguments of nouns, and clauses and APs are not possible arguments of nouns.

A) The selection restrictions of $-e r^{\text {Ev.restr }}$ permit it to merge with $\mathrm{V}^{\circ}$ but not with a phrasal projection. This has precedents in lexicalist analyses (e.g. Ackema \& Neeleman 2004:25, Grimshaw 1990:71) but can also be stated in syntactic theories that deny the existence of a generative lexicon or other presyntactic word-generating component. The insistence on $\mathrm{V}^{\circ}$ nonheads is stipulated in -er's selection restrictions. This is not a disadvantage, since any empirically responsible theory must stipulate selection restrictions for affixes, including competing accounts like those in (32).

B) $\quad-e r^{\text {Ev }}$ (in both variants $-e r^{\text {Ev.restr }}$ and $-e r^{\text {Ev.liberal }}$ ) realizes an Initiator argument (recall sections 2.1 and 3.2.2), which I express by treating it as a nominal Voice head which names an Initiator of the event described by V. Being a Voice head, $-e r^{\mathrm{Ev}}$ is licensed by an argument-structural [Initiator] feature on V (cf. note 13). Hence it cannot merge with V unless V's argument selection features are active (section 3.2.2), so arguments corresponding to V's internal arguments in clauses are obligatory in $-e r^{\text {Ev.restr }}$-nominals.

C) The selection restrictions of $-e r^{\text {Ev.restr }}$ license a structure $\left[\mathrm{N}^{\circ} \mathrm{V}^{\circ}-e r^{\text {Ev.restr }}\right]$ which could accommodate arguments of $\mathrm{V}$ if they merge with $\mathrm{V}$ in a base-generated complex head configuration $\left[\mathrm{N}^{\circ}\left[\mathrm{v}^{\circ} \mathrm{XV}\right]-\mathrm{er}^{\text {Ev.restr }}\right]$, which is arguably instantiated in wine drinkers. However, phrasal arguments cannot be part of a complex $\mathrm{V}^{\circ}$ and must thus be realized outside $\left[\mathrm{N}^{\circ} \mathrm{V}^{\circ}\right.$ $e r^{\text {Ev.restr }}$, as is standard in lexicalist accounts of nominalization (e.g. Grimshaw 1990:71, Ackema \& Neeleman 2004:23-27). (41) compares a clausal derivation with an $-r^{\text {Ev.restr- }}$

\footnotetext{
${ }^{19}$ The liberal/restrictive distinction does not entail "two grammars of English" (as a reviewer put it), but merely

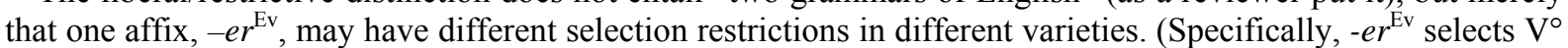
in restrictive varieties, as argued in section 4.2, while I tentatively assume that $-e r^{\text {Ev.liberal }}$ selects VP and unites with the verb via head movement.) Evidence that the liberal/restrictive distinction concerns the selection restrictions of individual affixes and is not a more general parameter is as follows. Adverbs like that in the washing of hands (\%thoroughly) are rejected by some speakers but perfect for others. We thus distinguish between -ing liberal, whose lexical entry licenses selection of a verbal (extended) projection large enough to accommodate adverbs (Fu et al. 2001) and -ing ${ }^{\text {restr }}$, which selects a smaller constituent. I find adverbs in -ingnominals perfect, and thus have $-i n g^{\text {liberal }}$. But my idiolect has $-e r^{\text {Ev.restr }}$, suggesting that there is not some kind of liberal-restrictive parameter that applies to all affixes for a given speaker. Open questions include whether any speakers display the reverse pattern $\left(-e r^{\text {Ev.liberal }}\right.$ but $\left.-i n g^{\text {restr }}\right)$, whether there are any implicational generalizations about restrictiveness, and, more generally, what factors lead language learners to postulate liberal or restrictive variants of nominalizers.
} 
nominalization. Nothing prevents merger of the PP below Voice in (a), while in (b) it must merge above Voice, since the Voice exponent selects $\mathrm{V}^{\circ}$.

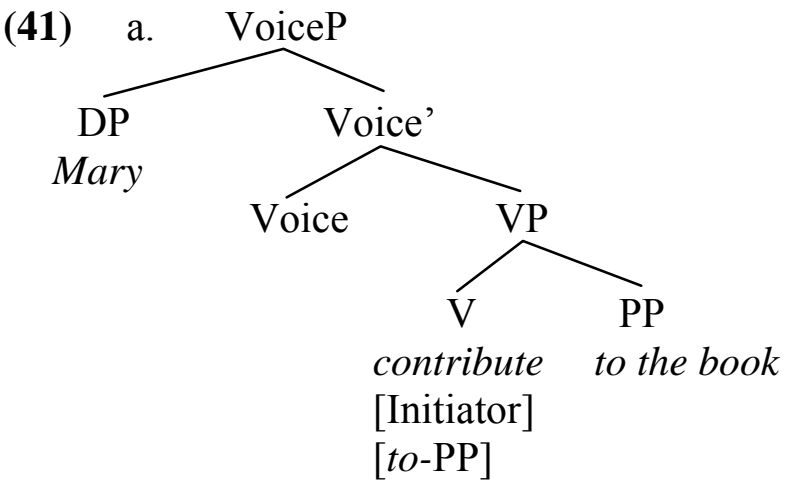

b.

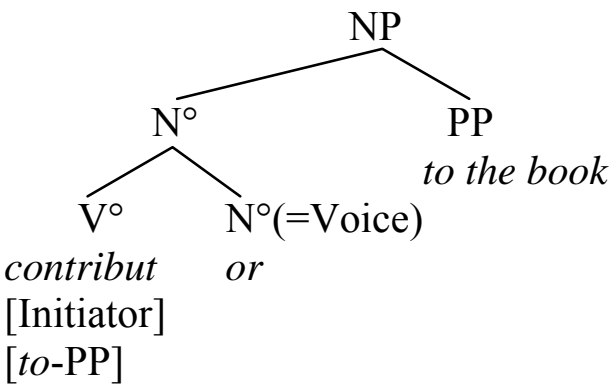

That V's otherwise 'internal' argument is coerced or 'squeezed out' to a position not immediately adjacent to $\mathrm{V}$ in (41)b) is a development of the idea that internal arguments of $\mathrm{V}$ may be initially merged at some distance from $\mathrm{V}$, which has precedents in the lexicalist tradition of argument inheritance and in empirical arguments that Themes/Patients of verbs in adjectival participles are 'externalized', i.e. initially merged outside the complex adjective (McIntyre 2013 and references).

Note that if indeed head movement overgenerates for $-e r^{\text {Ev.restr }}$, and if derivations like (41)b) and others below are needed, then Baker's (1988) Uniformity of Theta Assignment Hypothesis is counterexemplified, since certain arguments can merge as V-sisters in clauses but not in $-e r^{\mathrm{Ev}}$-nominals. My analysis also contradicts hierarchical linking theories, since they would have to assume, incongruously, that Agents are more prominent than other arguments in clauses but less prominent in certain nominalizations.

D) Whether arguments of $\mathrm{V}$ can be realized outside $\left[\mathrm{N}^{\circ} \mathrm{V}-\mathrm{er}^{\text {Ev.restr }}\right]$ depends on their ability to integrate into a nominal (extended) projection as arguments of nouns. I now argue that this is possible for PPs and DPs, but not CPs and AP complements.

D1) DP arguments realized using of-insertion are introduced above $-e r^{\text {Ev.restr }}$. Either the ofphrase merges directly with $\mathrm{N}$, as in (42)a), or as specifier of a functional projection, as in (42)b) (where $\mathrm{N}$ must move to a still higher functional head, say Number). Either way, ofphrases are independently available as a way of realizing DP arguments of underived nouns, cf. enemies of John, authors of books. ${ }^{20,21}$

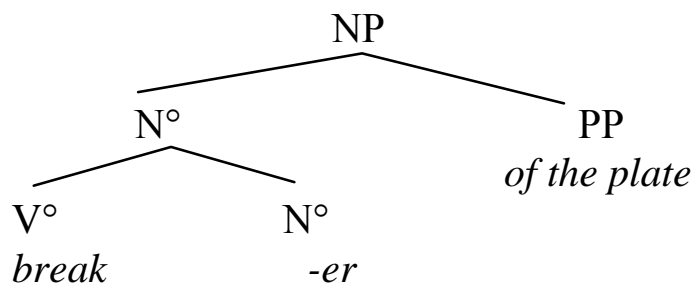

\footnotetext{
${ }^{20}$ Pace a reviewer, there is substantial evidence for treating of-phrases in nominalizations as inherited arguments and not as adjuncts. The adjunct analysis cannot explain for instance (i) Grimshaw's (1990:98) observation that modifiers but not arguments allow copula predication (*the destruction/destroyer was of Carthage vs. the ring was of gold), (ii) the fact that of-phrases systematically correspond to direct arguments of the nominalized verb and (iii) the fact that $-e r^{\text {nonEv }}$-nouns allow for-modifiers but not of-phrases (wiper for/*of windows). These are among the reasons why of-phrases are standardly treated as arguments in both syntactic theories (e.g. Alexiadou \& Schäfer 2010, Borer 2013, van Hout \& Roeper 1998) and lexicalist ones (Ackema \& Neeleman 2004, Grimshaw 1990).

${ }^{21}$ Whether prenominal genitives can realize inherited arguments in -er-nouns is unclear to me. Claiming that they are always possessors explains (i)-(ii) but not (iii). See also Rappaport \& Levin (1992:139).

(i) the car's owner/driver

(ii) *the bottle's drinker/opener

(iii) the city's destroyers/conquerors

[cars without owners/drivers]

[*bottles without drinkers/openers]

[*cities without destroyers/conquerors]
} 


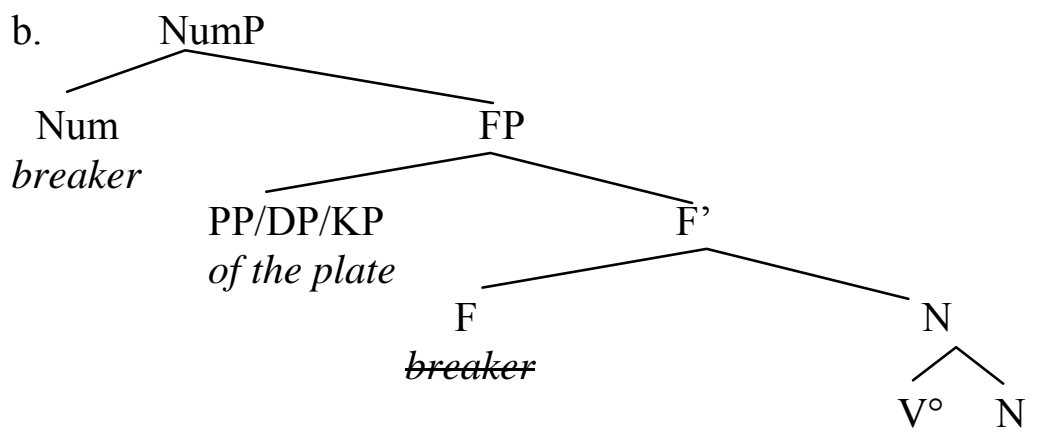

D2) The incompatibility of AP arguments with $-e r^{\text {Ev.restr }}$ seen in (35)a)/(36) $\left({ }^{\%}\right.$ hammerer of metal flat) is explained by the assumption that inherited arguments in -er-nominals are realized above -er and thus as arguments of nouns, and the fact that APs are not possible arguments of nouns, cf. (43)a). The desired interpretations are only possible using adjectival modifiers, (43)b). That depictive adjectives are bad with $-e r^{\text {Ev.restr }}\left({ }^{\%}\right.$ drinkers of tea hot) follows if depictives cannot be part of the $\mathrm{V}^{\circ}$ input to affixation.

(43) a. *his/the \{demeanour/air/appearance/belief/look\} sad

b. his sad demeanour; good lookers; careful worders of documents

D3) That PP arguments like (39) are compatible with $-e r^{\text {Ev.restr }}$ is unsurprising given that PPs are the commonest type of argument in underived nominals (faith in someone, concern for something). PPs like (40) are unacceptable to most speakers, even liberal ones, for reasons partly unclear to me. However, as noted below (40), these cases are more surprising in a head movement approach than the one espoused here.

D4) Grimshaw (1990.97ff) and Moulton (2013) show that DP-internal CPs/TPs like those in (44) are not arguments but (appositive) modifiers. Evidence for this includes that they are never obligatory and that they can be stranded by copulas, a property not found with genuine arguments, cf. (45).

(44) a. the $\{$ rumour/claim/point/view/idea/belief $\}$ that I am a crypto-lexicalist

b. the decision/attempt/instinct to love people

(45) a. The $\{$ belief/conclusion/hypothesis/idea $\}$ was that I am a crypto-lexicalist.

b. Their decision was \{to leave/that they should leave\}.

c. The arrangement/plan was for them to leave.

d. *The destruction/destroyer was of Carthage.

Whatever the explanation for the fact that CPs/TPs receive the appositive modifier interpretation if merged with $\mathrm{N}$, this interpretation is obviously nonsensical if they merge with entity-denoting nouns like -er-nominals and underived nominals (*a prophet/advocate that changes should occur). Indeed, my intuition as a $-e^{\text {Ev.restr }}$-speaker is that ${ }^{(*)}$ the discoverers that the world is round is deviant for the same reason as *the people that the world is round, namely that it is bizarre to assume that individuals 'are' propositions. ${ }^{22}$

I have argued that $-e r^{\text {Ev.restr }}$ requires a derivation where arguments of $\mathrm{V}$ merge after affixation of -er to $\mathrm{V}^{\circ}$. This structural configuration is like that assumed in lexicalist theories, but can be implemented in a syntactic approach. Some proponents of syntactic head movement approaches like those in (32) may consider my approach a retrograde step, but the onus is on them to show that the overgeneration problems facing their accounts can be solved.

\footnotetext{
${ }^{22}$ One informant accepted CP arguments in -er-nouns but rejected AP structures like (35). These judgments are less surprising than the reverse judgments, since simplex nouns disallow any kind of AP complement (*the demeanour/look sad) but do allow CP satellites like (44). Possibly this consultant treats the CPs in (44) as true arguments of nouns, contra the view adopted in the main text.
} 
If my discussion inspires successful responses to this challenge, or at least draws attention to data that have languished in obscurity since Grimshaw (1990), it will have been worthwhile.

\section{Conclusions}

I have sought to document the existence of two nominalization operations which restrict argument realization: (i) selection of morphological nonheads by non-argument-structuresensitive affixes like $-e^{\text {nonEv }}$, which renders (phrasal) arguments of nonheads unrealizable (section 3) and (ii) selection of morphological nonheads by argument-structure-sensitive affixes like $-e r^{\mathrm{Ev}}$, which forces phrasal arguments to be realized above affixation as arguments of nouns, thereby excluding AP and clausal arguments (section 4). Both analyses are inspired by certain lexicalist assumptions, and section 4 shows that the non-lexicalist tendency to use head movement to explain all argument inheritance phenomena courts overgeneration problems. However, neither analysis proposed here requires nominalization to occur in a presyntactic 'lexical' component, or excludes syntactic head movement derivations for nominalizations allowing unconstrained argument inheritance.

My attempt to discuss English -er in adequate detail left me with no space for discussion of other affixes. I intend to show elsewhere that the analyses of $-e r^{\text {nonEv }}$ and $-e r^{\text {Ev.restr }}$ apply to some other affixes, but that other analyses are appropriate for other category-changing processes showing constrained argument realization. Pending fulfilment of this promissory note, I hope that my treatment of -er will prove adequate, or at least draw attention to some empirical facts and analytic possibilities that will be useful in future accounts of argument inheritance with category-changing processes.

\section{References}

Ackema, P. \& Neeleman, A. 2004. Beyond Morphology. Oxford University Press.

Alexiadou, A. \& Schäfer, F. 2010. On the syntax of episodic vs. dispositional -er nominals. In A. Alexiadou \& M. Rathert (eds.) The syntax of nominalizations across languages and frameworks. Berlin: Mouton, 9-38.

Baker, M. 1988. Incorporation. Chicago University Press.

Baker, M. \& N. Vinokurova. 2009. On agent nominalizations. Language 85: 517-556.

Barker, C. 1998. Episodic -ee in English. Language 74: 695-727.

Borer, H. 2003. Exo-skeletal vs. Endo-skeletal explanations. In J. Moore \& M. Polinsky (eds). The nature of explanation in linguistic theory. Stanford: CSLI 31-67

Borer, H. 2013. Taking Form. To appear with OUP.

Bowers, J. 2011. Non-event nominals and argument structure. Lingua 121: 1194-1206.

Carrier, J., \& Randall, J. 1992. The argument structure and syntactic structure of resultatives. Linguistic Inquiry 23: $173-234$.

Collins, C. 2002. Eliminating labels. In S. Epstein \& D. Seely, Derivation and explanation in the minimalist program. Oxford: Blackwell.

Di Sciullo, A. \& Williams, E. 1987. On the Definition of Word. Cambridge (MA): MIT Press.

Dowty, D, 1991. Thematic Proto-Roles and Argument Selection. Language 67:547-619.

Fabricius-Hansen, Cathrine, 1993. Nominalphrasen mit Kompositum als Kern. Beiträge zur Geschichte der deutschen Sprache und Literatur 115: 193-243.

Fu, J., T. Roeper \& H. Borer. 2001. The VP within process nominals. NLLT 19: 549-582.

Gast, V.2008. Verb-noun compounds in English and German. Zeitschrift für Anglistik und Amerikanistik 56: 269-282.

Grimshaw, J. 1990. Argument Structure. Cambridge (MA): MIT Press.

Harley, H. 2008. Compounding in Distributed Morphology. In R. Lieber and P. Stekauer (eds.) The Oxford Handbook of Compounding. Oxford University Press.

Hudson, R. 2004. Are determiners heads? Functions of language 11: 7-42.

Knittel, M. 2010. Poessession vs. pseudo-incorporation in the nominal domain. The linguistic Review 22: $177-$ 230.

Kratzer, Angelika. 1996. Severing the External Argument from the Verb. In Phrase Structure and the Lexicon. Johan Rooryck and Laurie Zaring (eds.), 109-137. Dordrecht: Kluwer.

Landau, I. 2009. Saturation and reification in adjectival diathesis. Journal of Linguistics 45:315-361.

Levin, B. and M. Rappaport. 1986. The Formation of Adjectival Passives. Linguistic Inquiry 17: 623-662.

Levin, B. \& Rappaport, M. 1988. Nonevent -er nominals. Linguistics 26: 1067-1083. 
Levin, B., \& Rappaport Hovav, M. 1995. Unaccusativity. Cambridge, MA: MIT Press.

Lieber, R. 2004. Morphology and lexical semantics. Cambridge University Press.

McIntyre, A. 2013. Adjectival Passives and Adjectival Participles in English. In Artemis Alexiadou and Florian Schäfer, eds., Non-Canonical Passives, Amsterdam: Benjamins. 21-41.

Moulton, K. 2013. CPs: Copies and Compositionality. To appear in Linguistic Inquiry.

Naess, A. 2007. Prototypical transitivity. Amsterdam: Benjamins.

Olsen, S. 1992. Zur Grammatik des Wortes. Linguistische Berichte 137: 3-32.

Rainer, F. 2013. Agent and instrument nouns. In Peter Müller, Ingeborg Ohnheiser, Susan Olsen, Franz Rainer (eds.) Word-Formation. A Handbook of the Languages of Europe. Berlin: De Gruyter.

Randall, J. 1988. Inheritance. In W. Wilkins (ed.), Syntax and Semantics 21. New York: Academic Press. 129146.

Rappaport Hovav, M. \& Levin, B. 1992. -er nominals. Syntax and Semantics 26: 127-153.

Roy, Isabelle \& Soare, Elena. 2014. On the internal eventive properties of -er nominals. To appear in Lingua.

Ryder, Mary-Ellen 1999. Bankers and blue-chippers. English language and linguistics 3(2): 269-297.

Spalding, T. \& Gagné, C. Relation priming in established compounds. Memory \& Cognition 39: 1472-1486.

van Hout, A. and T. Roeper 1998. Events and aspectual structure in derivational morphology. MITWPL 32: 175200.

van Valin, R. 1999. Generalized semantic roles and the syntax-semantics interface. F. Corblin, C. DobrovieSorin \& J. Marandin, eds., Empirical issues in formal syntax and semantics 2. The Hague: Thesus, 373-389. 